\title{
Ultrasonography of hydronephrosis in the newborn: a practical review
}

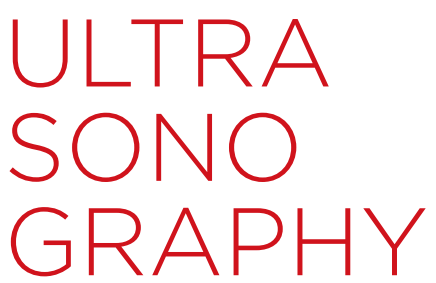

\author{
Young Hun Choi ${ }^{1}$, Jung-Eun Cheon ${ }^{1,2}$, Woo Sun Kim ${ }^{1,2}$, In-One Kim ${ }^{1,2}$ \\ 'Department of Radiology, Seoul National University College of Medicine, Seoul National \\ University Children's Hospital, Seoul; ${ }^{2}$ Institute of Radiation Medicine, Seoul National \\ University Medical Research Center, Seoul, Korea
}

Widespread use of fetal ultrasonography is accompanied by more frequent detection of antenatal hydronephrosis. Therefore, sonographic evaluation of neonates with a history of antenatal hydronephrosis is becoming more widespread. As an initial postnatal non-invasive imaging modality, ultrasonography is used to screen for persistence of hydronephrosis, determine the level and severity of obstruction, and contribute to appropriate diagnosis and treatment. This review aims to provide a practical overview of the sonographic evaluation of neonatal hydronephrosis and to describe the sonographic findings of conditions associated with hydronephrosis in the newborn.

Keywords: Hydronephrosis; Infant, newborn; Ultrasonography

\section{Introduction}

Hydronephrosis refers to the distension and dilation of the pelvocalyceal system. This condition is not equivalent to obstruction of the urinary tract, and only a portion of neonates with hydronephrosis subsequently show true obstruction of urine flow from the kidney due to structural or functional abnormalities [1,2]. Hydronephrosis is usually detected on prenatal ultrasonography (US), while neonates or young children with hydronephrosis may occasionally present with a palpable abdominal mass or complications of obstruction such as urinary tract infection or hematuria [3]. US remains the first-line imaging modality for confirming hydronephrosis and for determining the degree of dilation and the level of obstruction in neonates and young infants [2]. The purpose of this review is to discuss practical approaches and findings of US evaluation of the neonate with hydronephrosis.

\section{Antenatal Renal Pelvis Dilation}

Increasing US screening during pregnancy has led to increased detection of antenatal hydronephrosis, which refers to dilation of the renal collecting system in the fetus [4]. Antenatal hydronephrosis is one of the most common abnormalities detected at prenatal US, and is reported in $1 \%-5 \%$ of all pregnancies [4-6]. It is usually diagnosed by measurement of the anteroposterior diameter of the renal pelvis, although this measurement does not take into consideration calyceal or ureteral dilation or parenchymal changes, and therefore may not precisely reflect the severity of hydronephrosis $[4,7]$.

\begin{abstract}
This is an Open Access article distributed under the terms of the Creative Commons Attribution NonCommercial License (http://creativecommons.org/ licenses/by-nc/3.0/) which permits unrestricted noncommercial use, distribution, and reproduction in any medium, provided the original work is properly cited.
\end{abstract}

Copyright (C) 2016 Korean Society of Ultrasound in Medicine (KSUM)

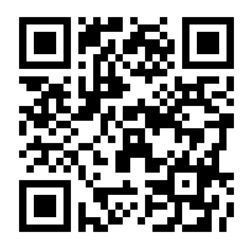

How to cite this article:

Choi YH, Cheon JE, Kim WS, Kim IO. Ultrasonography of hydronephrosis in the newborn: a practical review. Ultrasonography. 2016 Jul;35(3):198211. 
Antenatal hydronephrosis is indicated when the anteroposterior diameter of the renal pelvis is $\geq 4 \mathrm{~mm}$ in the second trimester or $\geq 7 \mathrm{~mm}$ in the third trimester [4]. It can be further graded as mild, moderate, or severe according to a set of anteroposterior diameter thresholds that have provided the best prognostic information based on available evidence (Table 1). According to this grading system, about two thirds of cases of antenatal hydronephrosis are regarded as mild [8].

It should be remembered that this finding of antenatal hydronephrosis is not necessarily a sign of obstruction, nor does it presage altered renal function. Nonetheless, there is a positive association between the degree of antenatal hydronephrosis and the incidence of significant postnatal pathology. In general, the greater the extent of dilation of the renal pelvis, the greater the possibility of significant anomalies [9]. Serial prenatal and postnatal US evaluations are recommended in all cases of antenatal hydronephrosis $[2,4,10]$.

\section{Initial Postnatal Sonographic Evaluation of Hydronephrosis}

All newborns with a history of antenatal hydronephrosis should undergo a postnatal US evaluation within the first week of life, even if the renal pelvic dilation was resolved prenatally [10]. US should not be performed until 4 days after birth because the relative dehydration and decreased glomerular filtration rate that are present immediately after delivery may lead to false-negative results or underestimation of the severity of hydronephrosis $[11,12]$. On the other hand, early neonatal US, within 1 or 2 days of birth, is required when there is bilateral hydronephrosis, severe hydronephrosis in a solitary kidney, or suspicion of posterior urethral valves [4].

The primary role of postnatal US is to confirm the presence of hydronephrosis. If dilation of the urinary system is detected, the severity and level of obstruction must be carefully evaluated. When performing US in neonates with hydronephrosis, each part of the urinary tract should be evaluated separately. The extent of dilation should be determined by measuring the anteroposterior diameter of the renal pelvis or the distal ureter, and in cases of severe hydronephrosis the thickness of the renal parenchyma should be also be determined. Additional specific US findings that should be noted include length of the kidneys, parenchymal echogenicity, cortico-medullary differentiation, and the presence of accompanying renal cysts. The bladder should also be evaluated for wall thickness and anomalies at the vesicoureteral junctions [2]. A 5.0- to 10.0$\mathrm{MHz}$ curved or linear array transducer, rather than the 3.0- to 5.0-MHz curved transducer that is used for adults, can maximize resolution during US imaging of the neonatal kidney. Each kidney
Table 1. Classification of antenatal hydronephrosis based on the anteroposterior diameter of the renal pelvis

\begin{tabular}{lcc}
\hline $\begin{array}{c}\text { Degree of antenatal } \\
\text { hydronephrosis }\end{array}$ & Second trimester $(\mathrm{mm})$ & Third trimester $(\mathrm{mm})$ \\
\hline Mild & 4 to $<7$ & 7 to $<9$ \\
Moderate & 7 to 10 & 9 to 15 \\
Severe & $>10$ & $>15$
\end{tabular}

Reproduced from Nguyen HT, et al. J Pediatr Urol 2010;6:212-231, with permission of Elsevier [4].

should be examined in transverse and longitudinal planes with the patient in a supine or decubitus position. Visualization of the upper poles of the kidneys can be improved by using the spleen or liver as an acoustic window, and scanning the patient in the prone position reduces the distance to the kidneys and enables the acquisition of better quality images.

To decrease intra- and inter-rater variation, hydronephrosis should be graded according to the Society for Fetal Urology (SFU) grading system [13] as follows: grade 1, mild dilation of the renal pelvis; grade 2, dilation of the renal pelvis with dilation of a few but not all of the calices; grade 3, nearly all calices are dilated; and grade 4, when there is parenchymal thinning (Fig. 1). This grading system has good intra-observer reliability and modest inter-observer reliability [14].

While the diagnosis of hydronephrosis is usually based on conventional gray-scale US, ancillary ultrasonographic techniques may be helpful for further evaluation. Pulsed Doppler examination of the intrarenal renal artery can differentiate between obstructive and non-obstructive hydronephrosis. In patients with obstructive hydronephrosis, diastolic arterial flow velocities are diminished and resistive index values are elevated because of vasoconstriction caused by renin, angiotensin, and other hormones [15]. A resistive index of $>0.7$ and a resistive index difference of $>0.10$ between kidneys in children are suggestive of renal obstruction, while a resistive index of $<0.70$ generally indicates non-obstructive dilation $[15,16]$. However, an increased resistive index is not specific for obstruction, because the resistive index can also be elevated in cases of medical renal disease and normal in patients with partial or chronic obstruction [15-17].

Color Doppler US may be useful for differentiating obstructive from non-obstructive causes of hydronephrosis in children via evaluation of ureteric jets in the bladder $[18,19]$. The frequency of ureteric jets on the affected side may be greatly reduced in comparison with the contralateral normal side in children with obstructive hydronephrosis $[18,19]$. Color Doppler is also very useful for differentiating a dilated pelvocalyceal system from prominent vessels in the renal hilum. Another supplementary modality, US 
elastography, has recently been applied in young children. The stiffness of the kidney on US elastography can be correlated with the degree of hydronephrosis [20]. Finally, three-dimensional US may provide more accurate information about the volume of the renal parenchyma and the overall size of the kidneys in children with hydronephrosis than conventional two-dimensional US [21].

\section{Follow-up Evaluation for Hydronephrosis}

For neonates with a history of antenatal hydronephrosis, normal findings at the initial postnatal US are not regarded as sufficient for confirmation of the absence of obstruction because of the low urine output and low glomerular filtration rate during the first week of life. A follow-up US is generally recommended at 4 to 6 weeks of age to confirm the absence of hydronephrosis [4]. A series of two normal postnatal renal US examinations can safely exclude obstructive hydronephrosis and dilating vesicoureteral reflux [22].

When the initial postnatal sonograms show mild dilation, patients are generally followed with sequential US examinations, because isolated dilation of the renal pelvis in the newborn period is resolved spontaneously in many cases [10]. A systematic review found that $98 \%$ of patients with mild hydronephrosis (SFU grade 1 or 2 ) have spontaneous resolution, improvement, or stabilization at followup [23]. Furthermore, it is reported that more than $90 \%$ of cases of moderate dilation of the renal pelvis (anteroposterior diameter 10 to $15 \mathrm{~mm}$ ) resolve spontaneously by 12 to 14 months of life [24].

If the postnatal sonogram shows moderate or severe hydronephrosis or dilated ureter(s), further evaluation is usually recommended $[4,10]$. Voiding cystourethrography is recommended to detect vesicoureteral reflux and lower urinary tract obstruction.

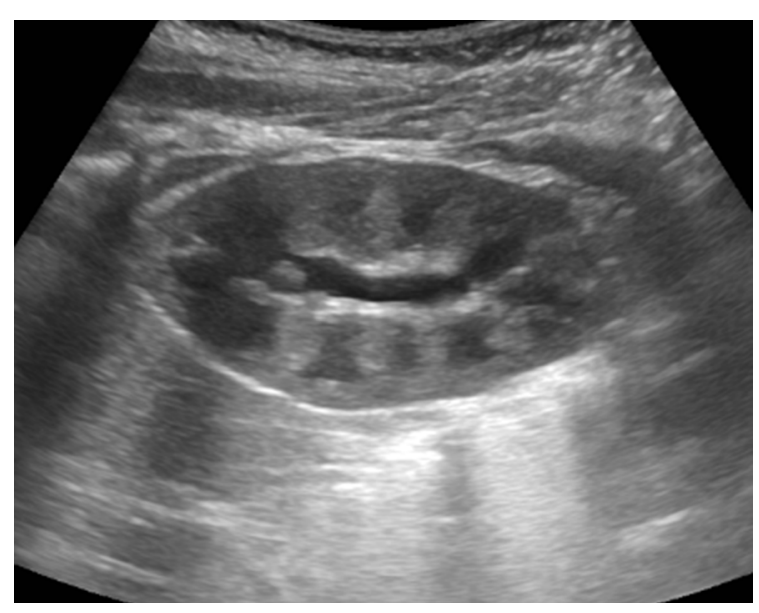

A

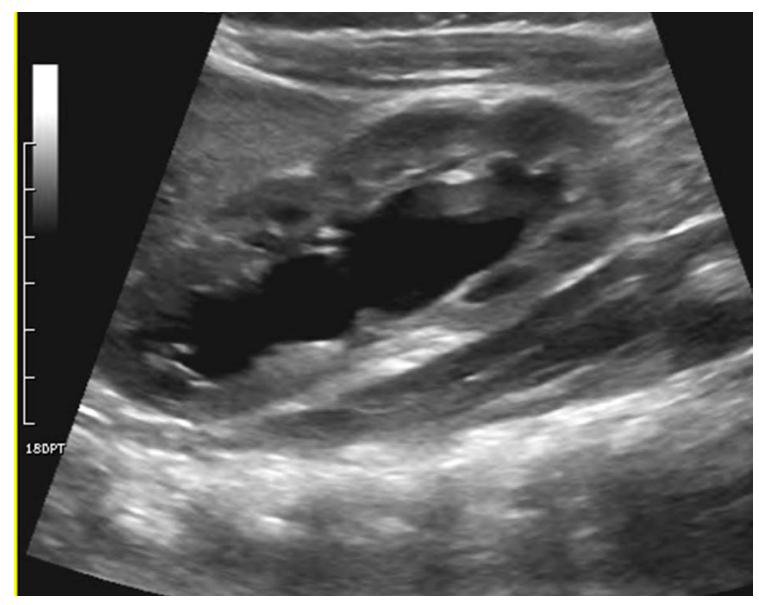

C

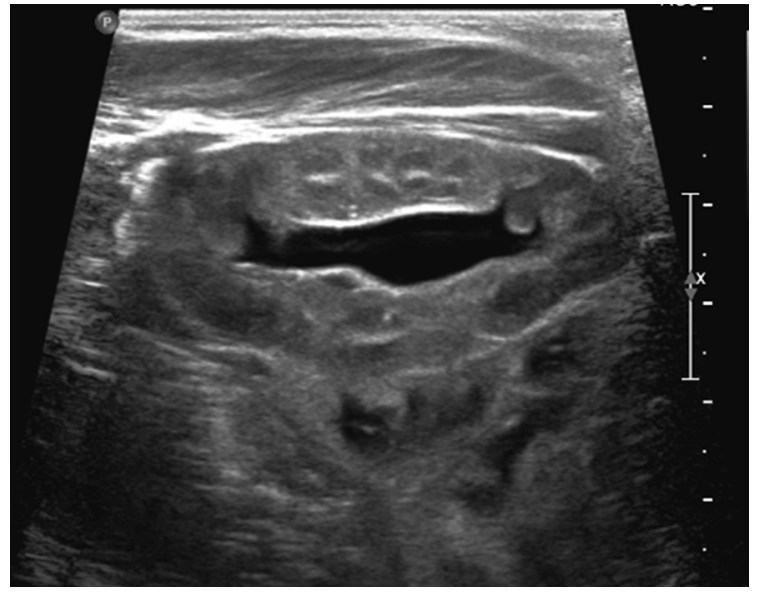

B

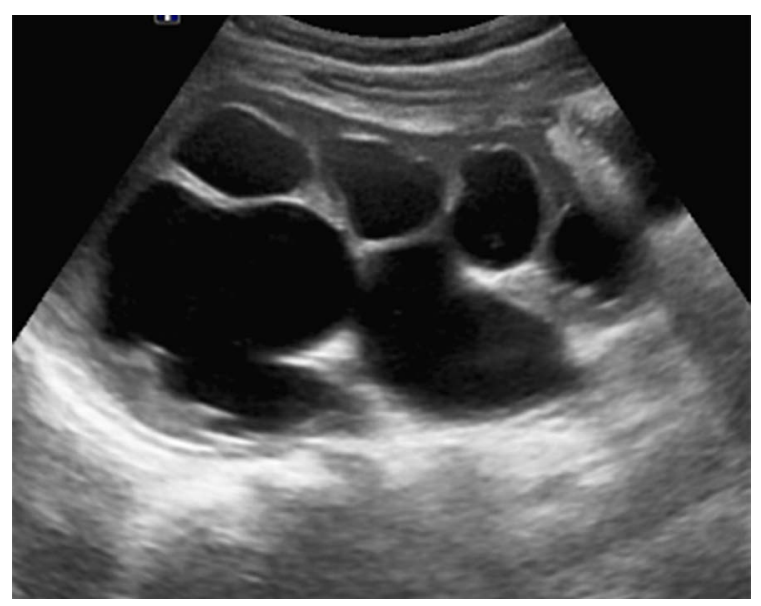

D

Fig. 1. Postnatal sonogram showing different grades of hydronephrosis according to the Society of Fetal Urology classification.

A. Grade 1: renal pelvis is mildly dilated without calyceal dilation. B. Grade 2: renal pelvis is further dilated and some calyces may be visualized. C. Grade 3: renal pelvis and minor calyces are diffusely dilated, but renal parenchyma is of normal thickness. D. Grade 4: as for Grade 3, but with thinning of the renal parenchyma over the dilated calyces. 
If there is no vesicoureteral reflux or lower urinary tract obstruction, a diuretic renal scan can be helpful to evaluate the nature of the obstruction and to determine the need for surgery by assessing renal perfusion, differential renal function, and excretion. Surgery is usually indicated only when the hydronephrosis is worsening or when there is a significant difference in function between kidneys. Recently, magnetic resonance (MR) urography has emerged as a promising alternative diagnostic modality that enables both anatomical and functional evaluation of the urinary system without radiation exposure $[25,26]$. MR urography promises greater tissue contrast and better spatial and temporal resolution than diuretic renal scanning, and thus provides valuable information on differential diagnosis and renal function during surgical planning [27].

In patients with spontaneous resolution of hydronephrosis confirmed through serial US examinations, a repeat US should be performed 3 to 6 months later to confirm the finding because of the possibility of recurrence [28]. All grades of stable but persistent hydronephrosis require long-term follow up because there is a low but not negligible possibility of late worsening [4]. The risk of recurrence or late worsening of hydronephrosis is approximately $1 \%-5 \%$ and applies to all grades of hydronephrosis [29-31]. Furthermore, in cases of late worsening or recurrence of hydronephrosis, the majority of patients become symptomatic and will present with high-grade (grade 3 to 4 ) hydronephrosis [30]. The timing of late worsening or recurrence reportedly ranges from a few months to 5 to 6 years. In light of the low incidence of recurrence or late worsening, future prospective studies would be required to determine the most clinically appropriate and cost-effective length
Table 2. Differential diagnosis of perinatal hydronephrosis

\begin{tabular}{|c|c|}
\hline Etiology & Percentage \\
\hline Transient hydronephrosis & $41-88$ \\
\hline Ureteropelvic junction obstruction & $10-30$ \\
\hline Vesicoureteral reflux & $10-20$ \\
\hline Ureterovesical junction obstruction/megaureter & $5-10$ \\
\hline Multicystic dysplastic kidney & $4-6$ \\
\hline Duplex kidney/ureterocele & $5-7$ \\
\hline Posterior urethral valve/urethral atresia & $1-2$ \\
\hline $\begin{array}{l}\text { Others: prune belly syndrome, cystic kidney disease, } \\
\text { congenital ureteric strictures }\end{array}$ & Uncommon \\
\hline
\end{tabular}

of surveillance for children with antenatal hydronephrosis [4].

\section{Etiology of Perinatal Hydronephrosis}

The etiology of perinatal hydronephrosis includes transient dilation of the collecting system, upper/lower urinary tract obstructive uropathy, and non-obstructive processes such as vesicoureteral reflux (Table 2). In the following sections, we will review characteristic US findings of several common and important diseases that can present with hydronephrosis in the newborn period.

\section{Transient Hydronephrosis}

Most cases of mild isolated unilateral or bilateral hydronephrosis on prenatal US ultimately resolve $[4,32,33]$. The incidence of transient hydronephrosis is between $41 \%$ and $88 \%[6,34,35]$. The etiology of

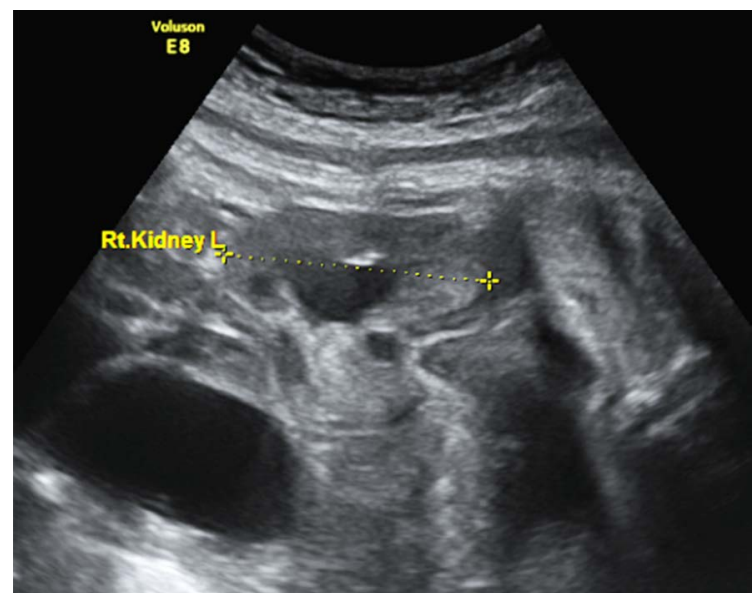

A

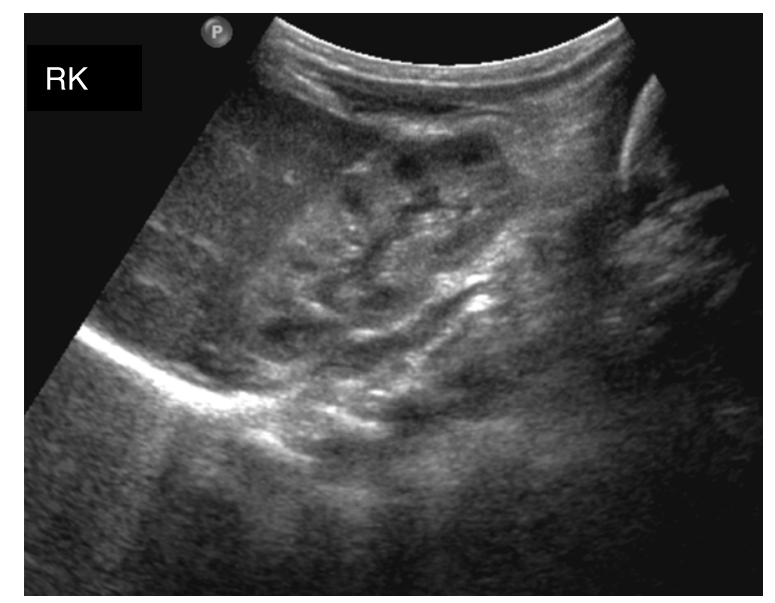

B

Fig. 2. Representative sonogram of transient hydronephrosis in a neonate.

A. Isolated dilation of the renal pelvis is seen on prenatal ultrasound scan at 37 weeks of gestation. B. First postnatal ultrasonography, obtained at day 4 after birth, shows complete resolution of the dilation. RK, right kidney. 
transient hydronephrosis is still elusive, but it appears that immature and poorly coordinated peristalsis of the smooth muscle of the renal pelvis leads to inadequate emptying and resultant urinary stasis within the renal pelvis [28]. The timing of resolution varies considerably, but it usually occurs during the first few years of life [4]. Earlier resolution is expected for milder grades of hydronephrosis, with most cases of SFU grade 1 to 2 hydronephrosis resolving by 18 months of age [6]. The differentiation of transient hydronephrosis from true ureteropelvic junction obstruction is virtually impossible with a single US examination, and serial follow-up with US is

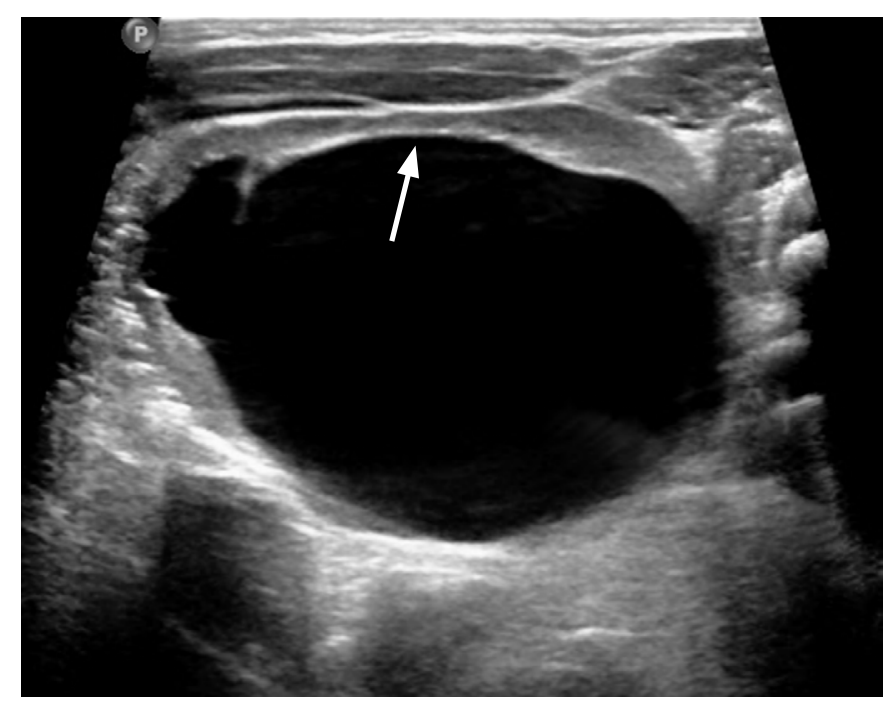

A recommended until resolution (Fig. 2) $[4,10]$.

\section{Ureteropelvic Junction Obstruction}

Ureteropelvic junction obstruction is defined as the functional or anatomic obstruction of urine flow at the ureteropelvic junction. Ureteropelvic junction obstruction is the most common cause of obstructive hydronephrosis in neonates and shows a male and left-side predominance $[2,36]$. Ureteropelvic junction obstruction can be caused by abnormally developed ureteral smooth muscle at the ureteropelvic junction, resulting in an aperistaltic segment. Other intrinsic (intrinsic stenosis, valve or folds, fibrous bands) and extrinsic (abnormal vessels crossing the upper ureter or renal pelvis) factors have also been implicated as causes of ureteropelvic junction obstruction [37]. Ultrasonographic findings of ureteropelvic junction obstruction follow the general rule of obstruction: dilation of the upstream structure and collapse of the downstream structure beyond the transition point. US of the involved kidney shows multiple dilated calyces of uniform size that communicate with a dilated renal pelvis with abrupt narrowing at the level of the ureteropelvic junction in the absence of dilated ureter on a scan through the bladder (Fig. 3) [3]. In more severe cases, the renal parenchyma gets thinner. Cases of severe in utero obstruction may be accompanied by findings including renal dysplasia, subcapsular urinoma, and urine ascites. Sonographic features of renal dysplasia include increased parenchymal echogenicity, loss of corticomedullary differentiation, and the advent of cortical cysts (Fig. 4) [38].

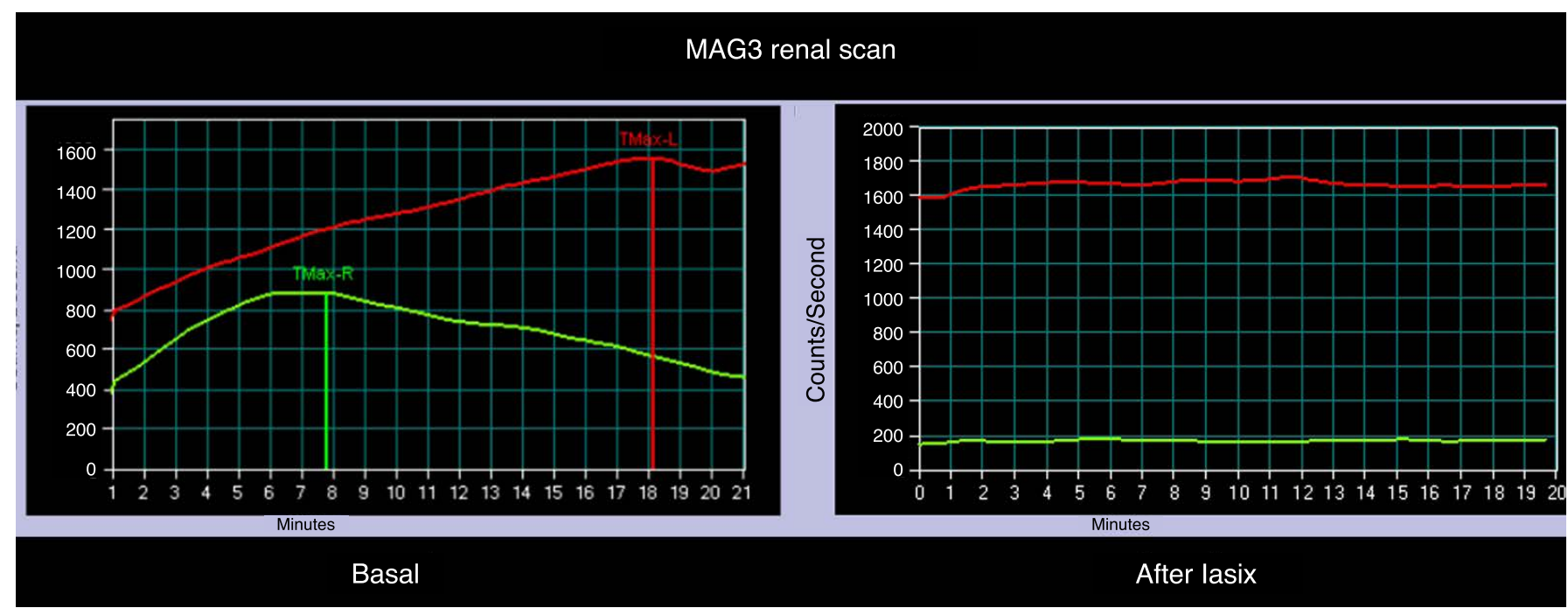

B

Fig. 3. Ureteropelvic junction obstruction: hydronephrosis detected on prenatal ultrasonography.

A. Longitudinal sonogram of the left kidney obtained 5 days after birth reveals severely dilated pelvocalyces. There is thinning of the overlying renal parenchyma (arrow). B. MAG3 diuretic renal scan shows that there is no clearance of the radiotracer from the left kidney even after injection of furosemide injection. All these findings are consistent with ureteropelvic junction obstruction. 


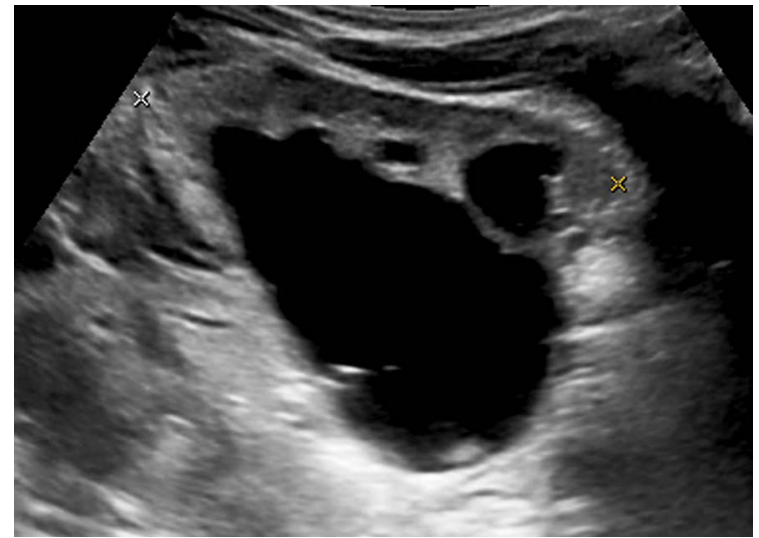

A

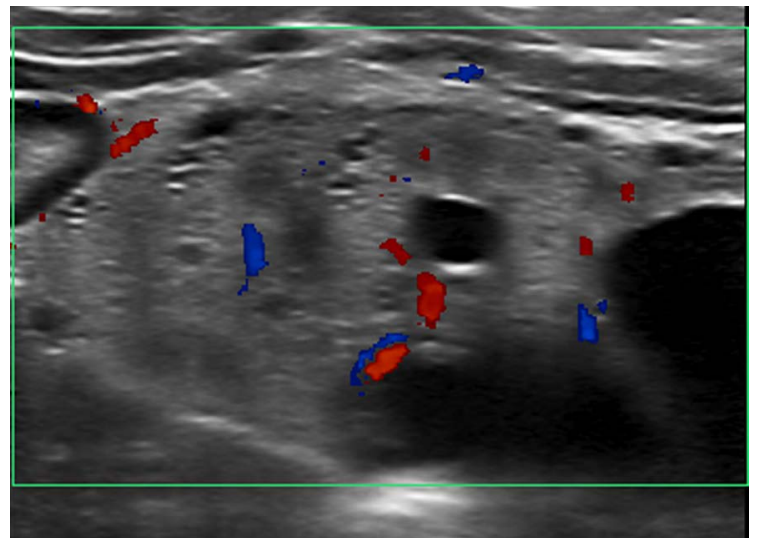

B

Fig. 4. Renal dysplasia associated with ureteropelvic junction obstruction.

A. Hydronephrotic right kidney shows increased parenchymal echogenicity with loss of cortico-medullary differentiation. B. Ultrasonography obtained with a high frequency linear probe shows multiple small renal cysts.

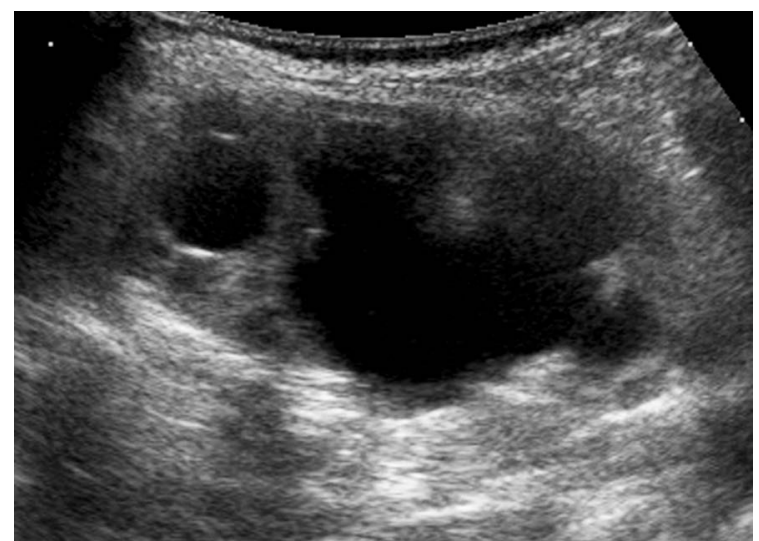

A

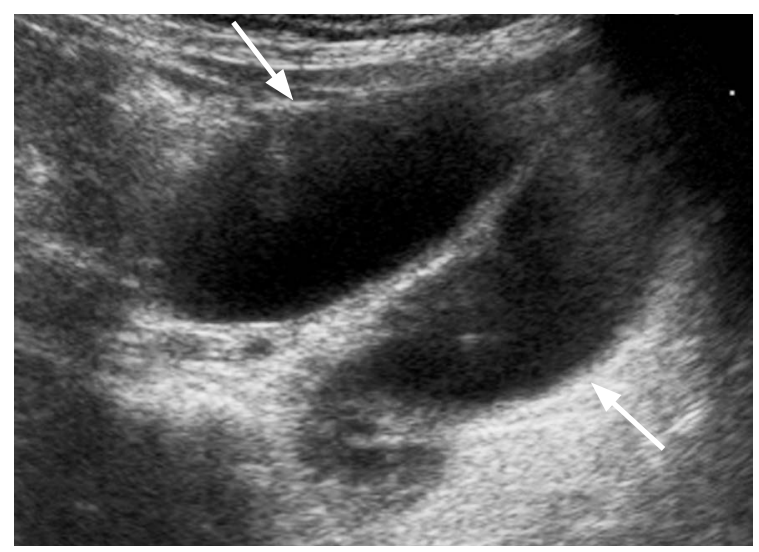

B

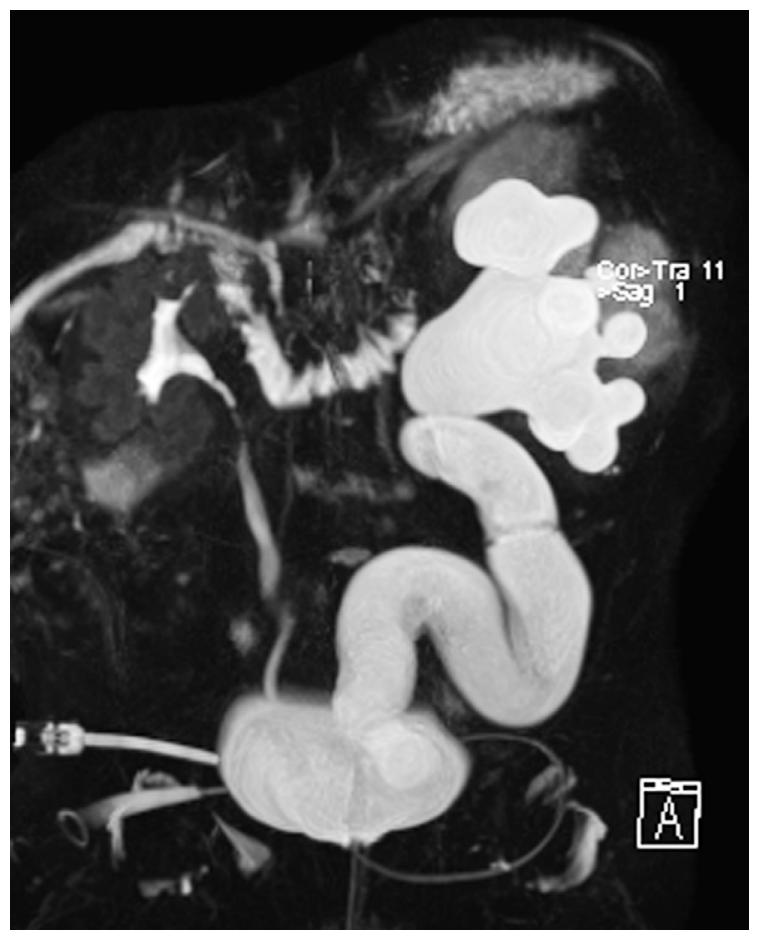

C

Fig. 5. Primary obstructed megaureter.

A. Longitudinal sonogram of the left kidney in a 1-month-old female infant shows significant dilation of the pelvocalyceal system. B. In addition, there is diffuse dilation along the course of the left ureter (arrows). No reflux is identified on voiding cystourethrography (data not shown). C. Magnetic resonance urography confirming significant dilation of the entire length of the left ureter and of the pelvocalyceal system. This patient underwent ureteroneocystostomy and no anatomic narrowing was identified at the ureterovesical junction. 


\section{Megaureter}

Megaureter is a descriptive term referring to a dilated ureter $[3,39]$. This condition can be induced by various factors. Any abnormalities involving the distal ureter, bladder, or urethra, including congenital distal ureteral stricture, distal ureteral valve, ureterocele, neurogenic bladder, bladder outlet obstruction, posterior urethral valve, calculi, blood clot, or polyp, can lead to dilation of the ureter. Primary megaureter refers to ureteral dilation without an identifiable anatomic cause at the vesicoureteral junction [40]. There are three types of primary megaureter: obstructed primary megaureter, refluxing primary megaureter, and nonrefluxing unobstructed primary megaureter $[2,40]$. In primary obstructed megaureter, the most distal part of the ureter is adynamic and unable to conduct a peristaltic wave, producing a functional obstruction similar to that observed in achalasia or Hirschsprung's disease $[40,41]$. US features of primary megaureter include fusiform dilation of the distal third of

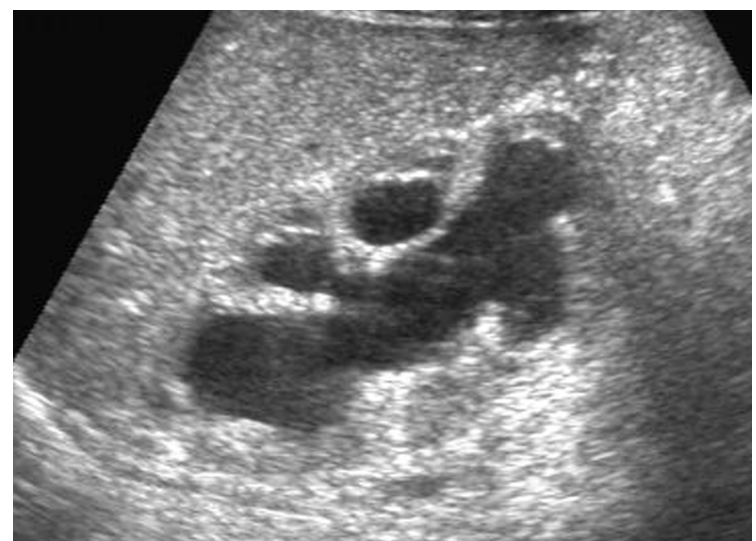

A

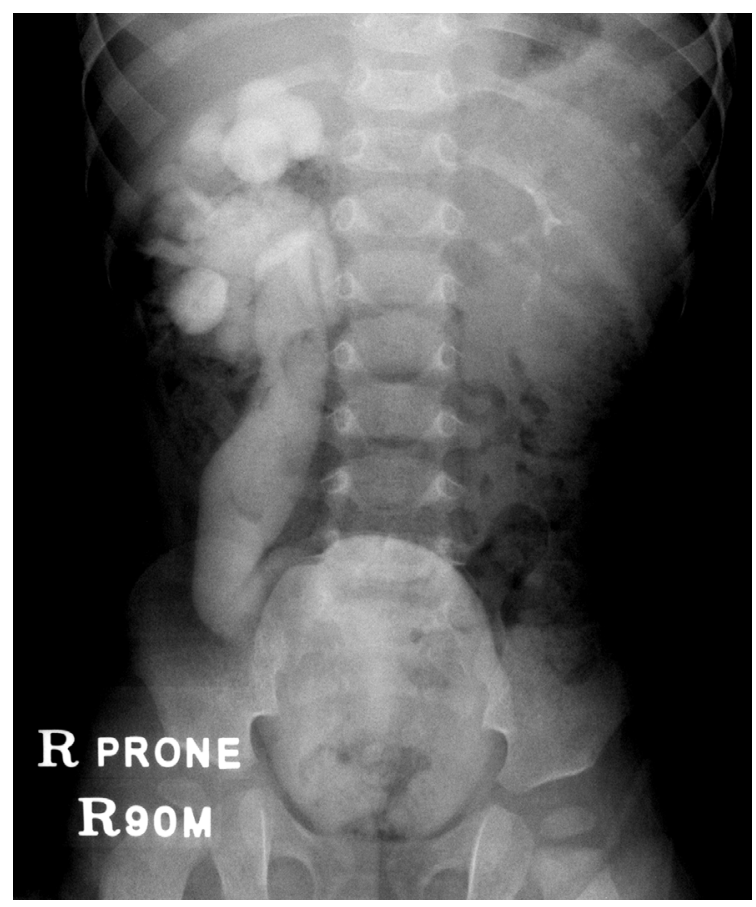

C

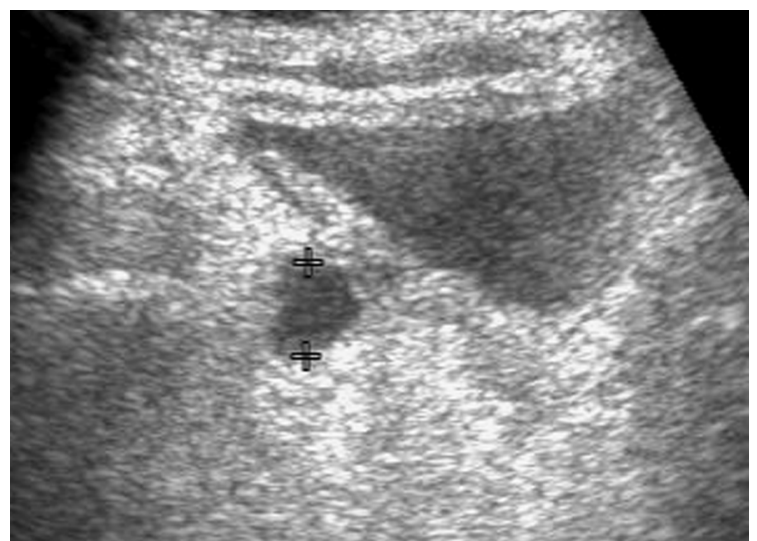

B

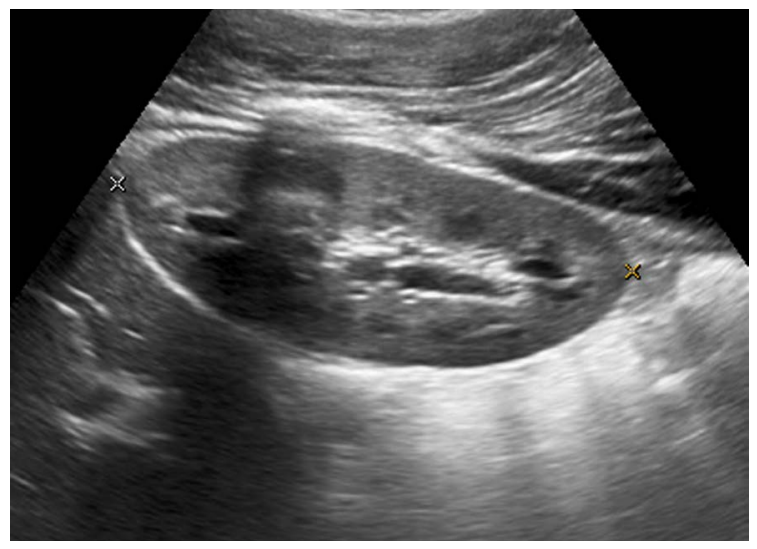

D

Fig. 6. Spontaneous resolution of primary megaureter.

A, B. Marked dilation of the right pelvocalyces and ureter in a 20-day-old neonate. The right ureter is indicated by cross marks (B). C. Intravenous pyelogram obtained 90 minutes after contrast administration revealed significant dilation of the entire excretory system on the right side. Dynamic renal scintigraphy showed excretion of the isotope after a diuretic challenge (data not shown). D. The patient was followed clinically without any intervention, and ultrasonography at 12 years of age shows near-complete spontaneous resolution of the hydroureteronephrosis. 
the affected ureter proximal to its insertion into the bladder and a smooth, tapered, adynamic far distal ureter on real-time examination
(Fig. 5) [3]. At cystoscopy, primary megaureter is characterized by a normal ureteral orifice without true organic narrowing of the

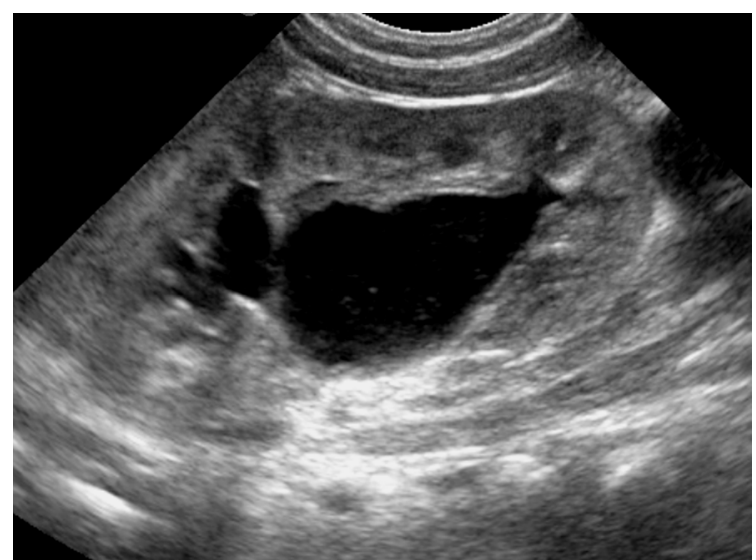

A

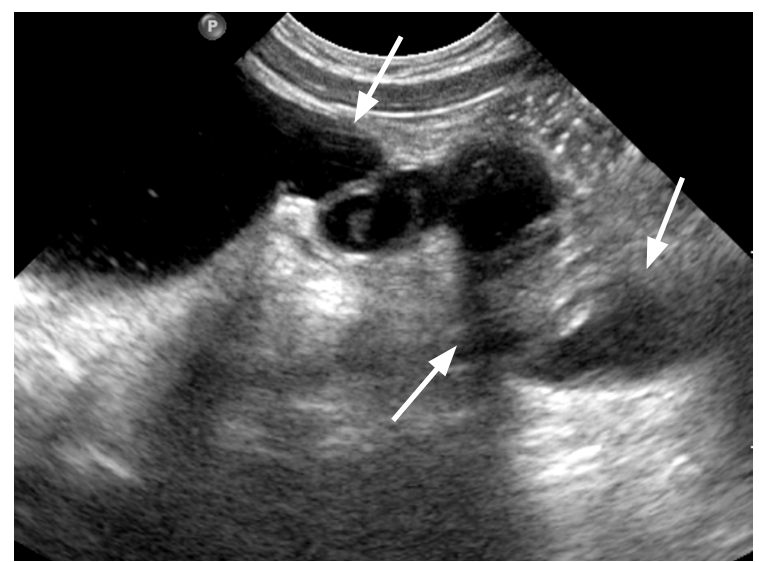

B

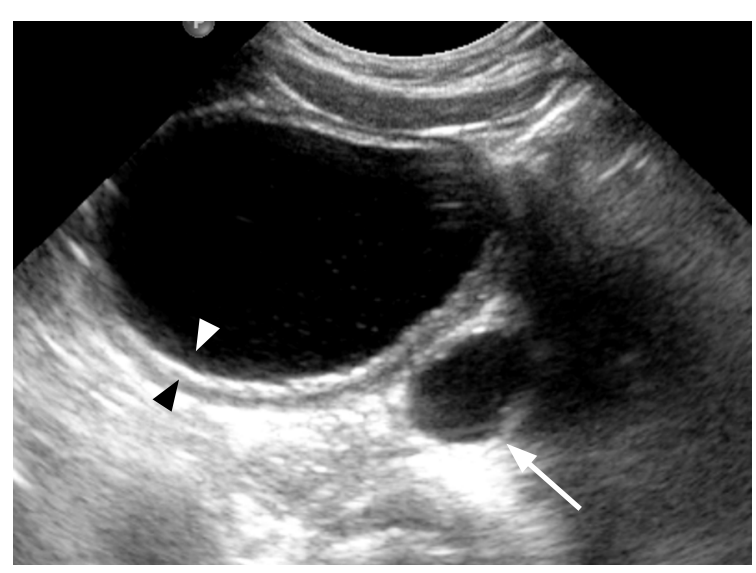

C

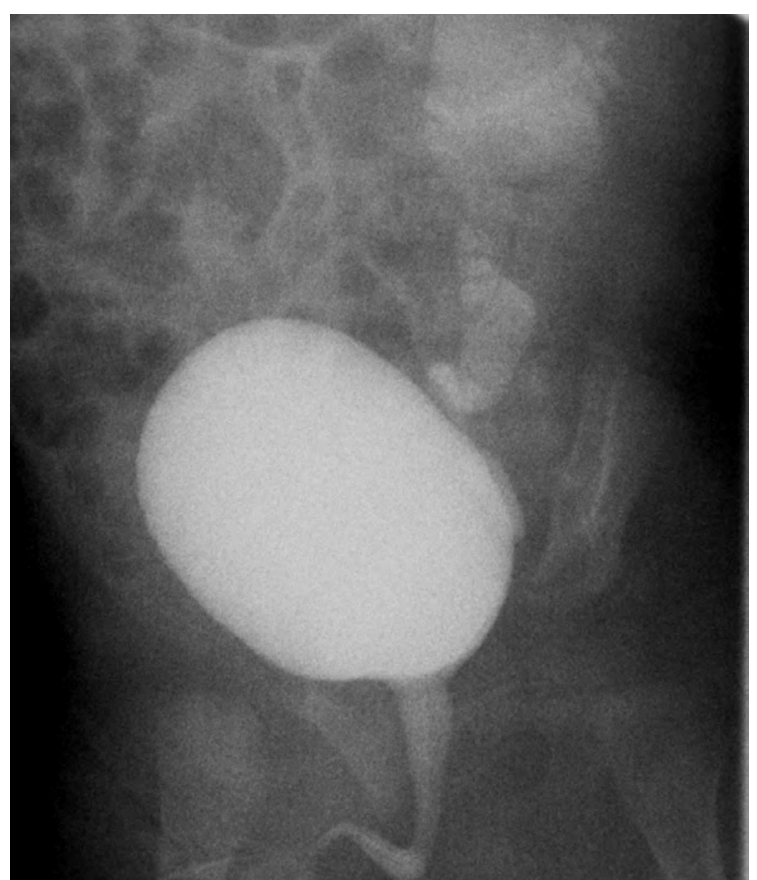

D

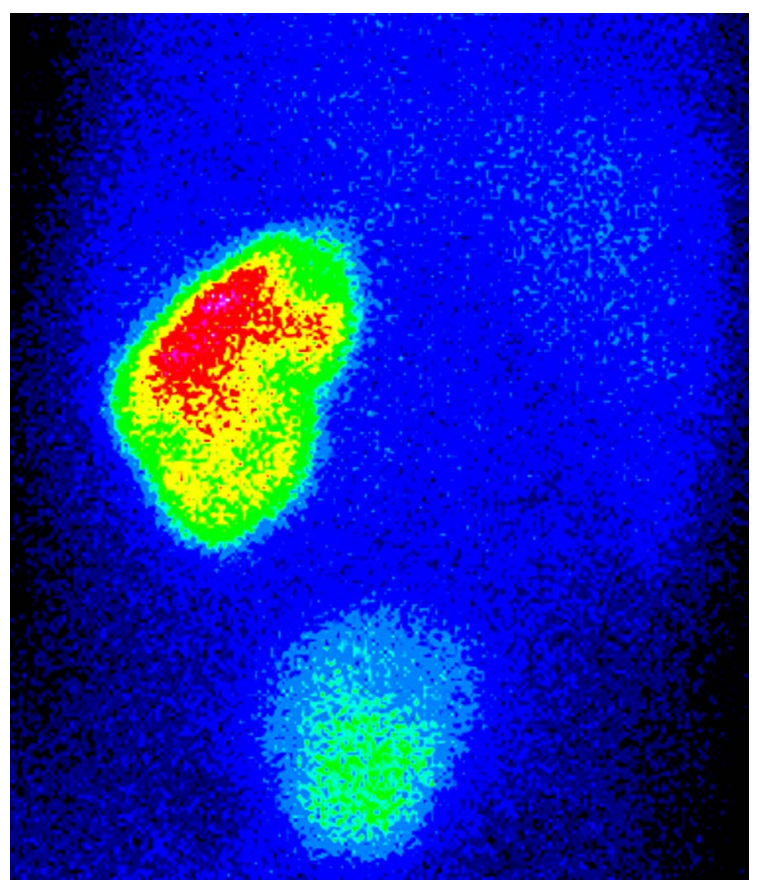

$\mathrm{E}$

Fig. 7. Vesicoureteral reflux in a patient with a single kidney.

A, B. Left ureter (arrows) is diffusely dilated and the left renal pelvis and calyces are dilated. C. Diffuse thickening of the bladder wall (arrowheads) and dilation of the retrovesical ureter (arrow) are noted. D. Voiding cystourethrogram confirms a high-grade reflux into the single urinary system. E. Posterior view of the ${ }^{99 m} \mathrm{Tc}$ CDMSA renal scintigraphy confirms a single left kidney. In cases of single kidney, various anomalies including vesicoureteral reflux or ureteropelvic junction obstruction may coexist at the single kidney. 
distal ureter when probing with a ureteral catheter [40]. Ipsilateral megacalycosis and vesicoureteral reflux may also present. Primary megaureter of the nonobstructive variety can resolve spontaneously (Fig. 6) [42]. In such cases, primary megaureter is thought to be related to functional immaturity of the ureter [39].

\section{Vesicoureteral Reflux}

Vesicoureteral reflux refers to the retrograde passage of urine from the urinary bladder to the ureter and often to the calyces [40]. Vesicoureteral reflux is thought to be caused by a developmental anomaly at the ureterovesical junction in which the ureteral orifice may be lateralized or too large or the submucosal ureter is too short or deficient in longitudinal muscle fibers [43]. Immaturity of the ureterovesical junction may contribute to some extent [43]. Patients with vesicoureteral reflux can present in the neonatal period with antenatally detected hydronephrosis or urinary tract infection. The severity of vesicoureteral reflux can be graded based on the appearance of the upper urinary tract on voiding cystourethrogram [44]. Vesicoureteral reflux can disappear spontaneously as the ureterovesical junction matures during the first decade of life. Mild vesicoureteral reflux (grade 1 and 2) has a favorable prognosis and disappears with time in more than $80 \%$ of cases, while more severe forms have a lower incidence of spontaneous resolution $[43,45]$. Vesicoureteral reflux associated with anatomic anomalies such as lateral ectopia of the lower moiety ureter in a duplex kidney or paraureteral diverticulum is not likely to resolve spontaneously. Vesicoureteral reflux is a risk factor for upper urinary tract infection and pyelonephritis with consequent renal scarring and potential long-term sequelae such as end-stage renal disease or hypertension.

The features of vesicoureteral reflux on conventional US are nonspecific. The walls of the renal pelvis and ureter may be thickened, presumably because of in-folding of the epithelium of the intermittently dilated collecting system during reflux while the dilated urinary tract empties [46]. The finding of a changing degree of hydronephrosis or hydroureteronephrosis may indicate the presence of vesicoureteral reflux. However, there is no one pathognomonic feature for the definitive diagnosis of vesicoureteral reflux on conventional US (Fig. 7) [4], and it is important to realize that a normal urinary sonogram dose not exclude reflux [40]. Therefore, contrast-enhanced voiding US, which assists with diagnosis and grading of vesicoureteral reflux while avoiding exposure to ionizing radiation, and can detect vesicoureteral reflux directly, may also be indicated $[47,48]$. This modality involves instillation of contrast material into the urinary bladder via catheter and monitoring of its retrograde passage from the bladder to the ureter and the renal pelvis via alternatively scanning both kidneys and the bladder during filling and before and after voiding.

\section{Multicystic Dysplastic Kidney}

Multicystic dysplastic kidney is a subtype of renal dysplasia characterized by the presence of multiple, variable sized, noncommunicating cysts in the absence of normal renal parenchyma (Fig. 8) [49]. Severe ureteral obstruction early in the gestation period is thought to lead to this condition [38]. Most cases are correctly identified in utero with US [4]; postnatal US findings consistent with multicystic dysplastic kidney will also suffice to confirm the diagnosis in most cases [36]. In addition to confirming the diagnosis, postnatal US in neonates with a multicystic dysplastic kidney is also performed to check for associated anomalies in the contralateral unaffected kidney. Vesicoureteral reflux or ureteropelvic or ureterovesical

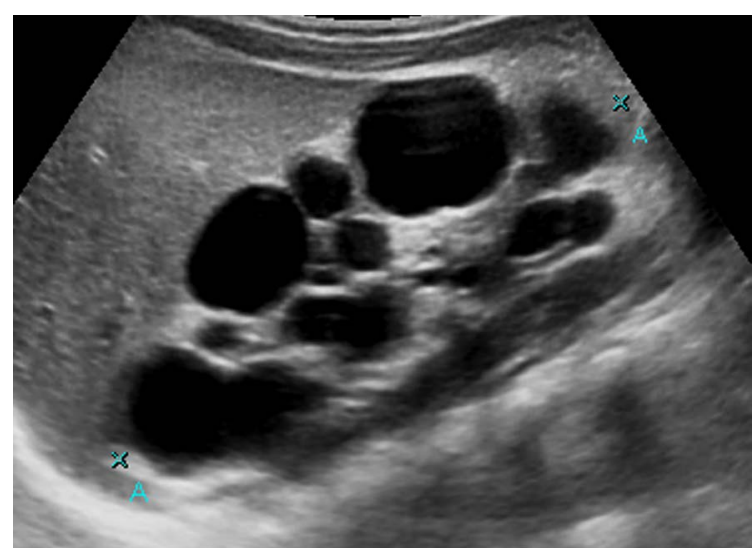

A

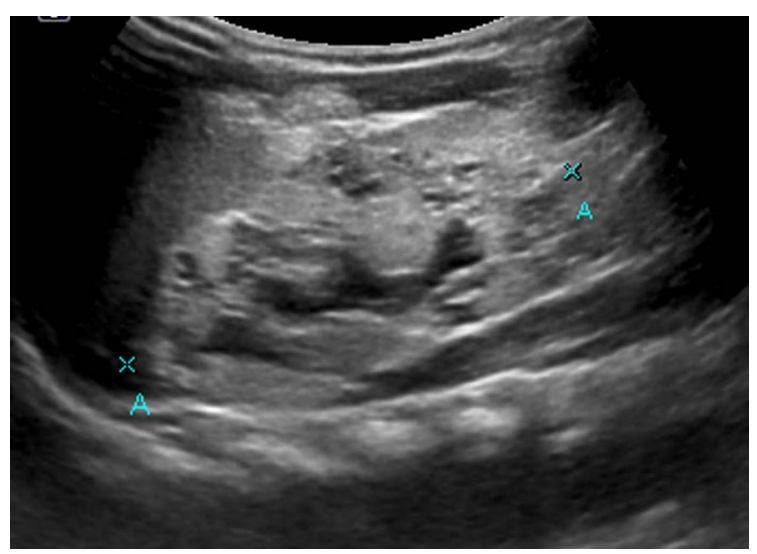

B

Fig. 8. Multicystic dysplastic kidney with a contralateral dysplastic kidney in a 1-month-old male infant.

A. Longitudinal sonogram of the right kidney shows multiple variable sized cysts in the absence of normal renal parenchyma, mimicking hydronephrosis. B. Longitudinal sonogram of the left kidney shows a relatively small, echogenic kidney with multiple tiny cysts, which implies the presence of renal dysplasia in the contralateral kidney and points to a poor prognosis. 
junction obstruction has been reported in the contralateral kidney in up to $50 \%$ of cases, and such abnormalities are of great clinical concern [36]. Unlike severe hydronephrosis, in which the centrally located renal pelvis is the most greatly distended and communicates with the surrounding dilated calyces, the distribution of the cysts in cases of multicystic dysplastic kidney is without a recognizable pattern [38]. Multicystic dysplastic kidney usually shrinks or disappears spontaneously over time.

\section{Duplex Kidney}

Duplex kidney defines a single renal unit that is drained by two collecting systems. Forms of duplex kidney range from bifid renal pelvis to incomplete or complete ureteral duplication [50]. Clinically, complete duplication may present with hydronephrosis

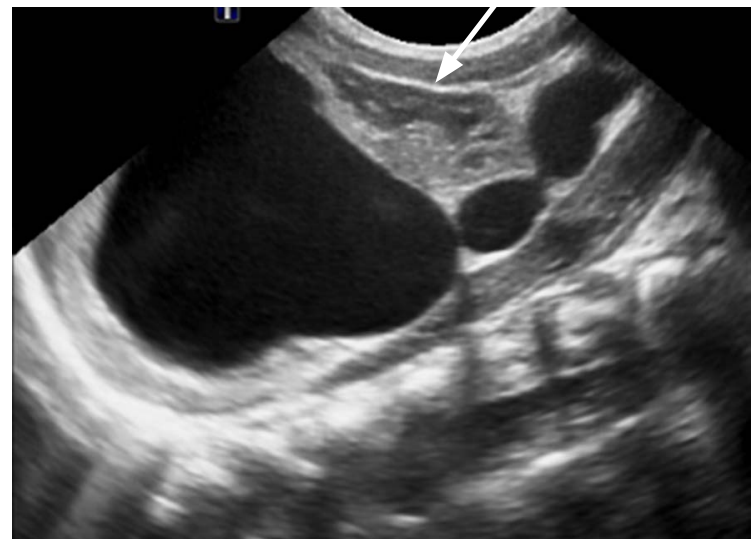

A

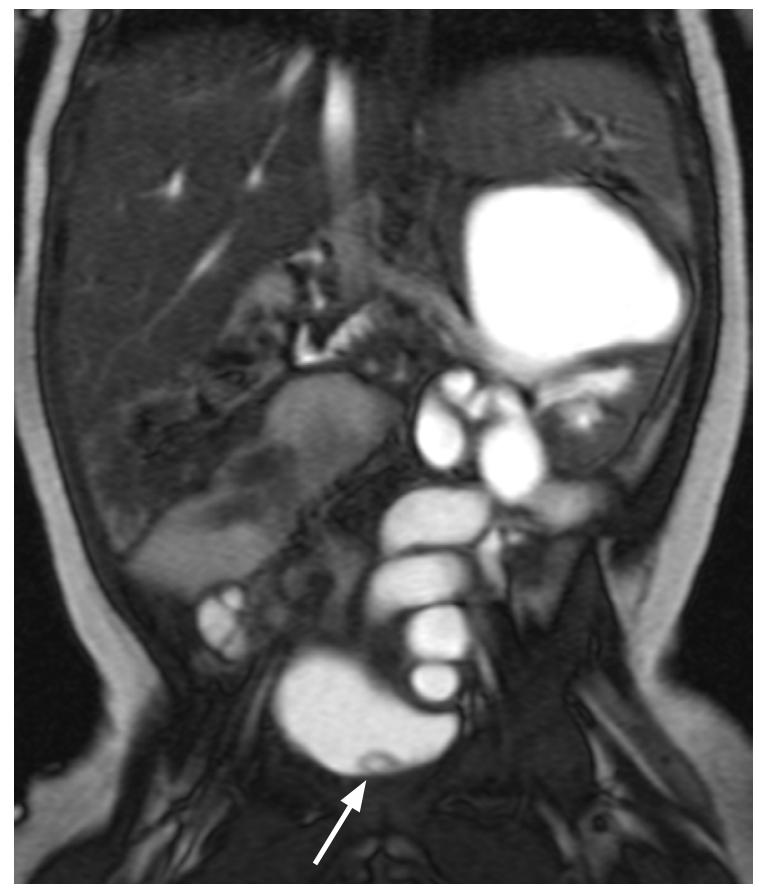

C

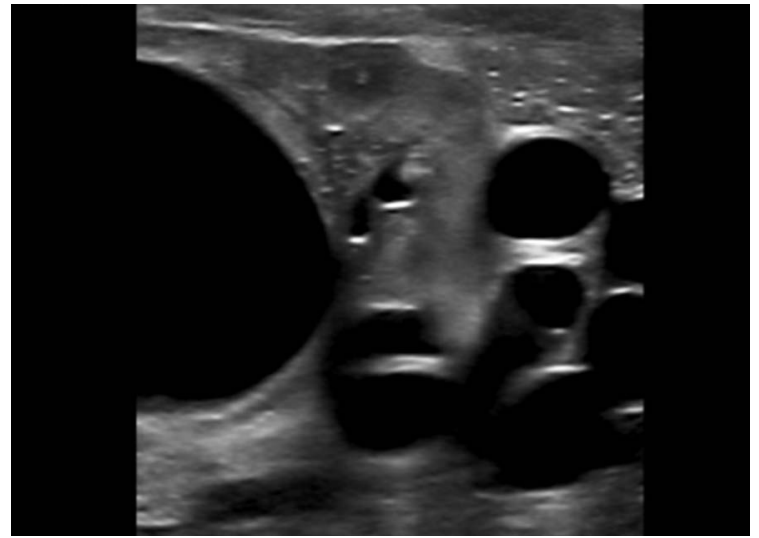

B

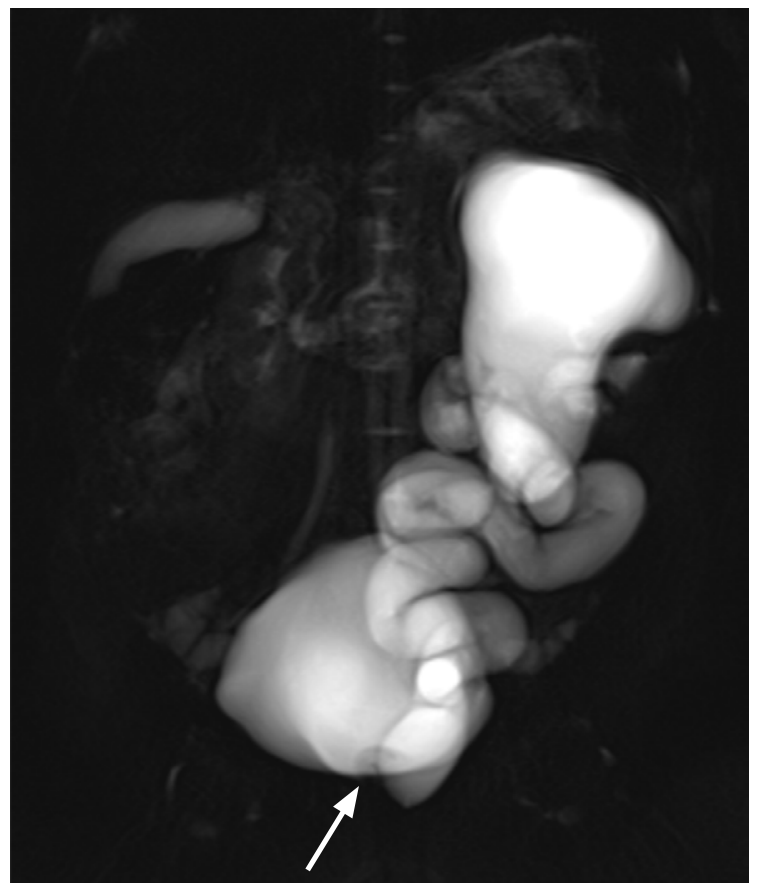

D

Fig. 9. Complete ureteral duplication in a neonate.

A. Longitudinal sonogram of the left kidney reveals severe dilation of the collecting system at the upper pole with overlying cortical thinning. There is no significant pelvocalyceal dilation at the lower pole (arrow). B. Sonogram obtained with a high-frequency linear probe shows the demarcation between the upper and lower moieties. C, D. Coronal balanced steady-state free precession (C) and thick-slab half-Fourier acquisition single-shot turbo spin-echo magnetic resonance (D) images confirm marked dilation of the excretory system from the upper moiety. There is a small intraluminal cystic structure (arrow) in the bladder, which is indicative of a ureterocele connected to the dilated upper pole ureter. 
in the neonatal period [2]. Cases of complete duplication will almost always follow the Weigert-Meyer rule, i.e., the ureter from the upper moiety inserts distally and medially and frequently ends as an ureterocele or an ectopic ureter while the ureter from the lower moiety inserts more cranially and laterally and often has a perpendicular course, predisposing it to reflux $[40,41]$. The ectopic ureter can insert into various locations according to gender, including bladder neck, urethra, vestibule, vagina, or uterus in girls,

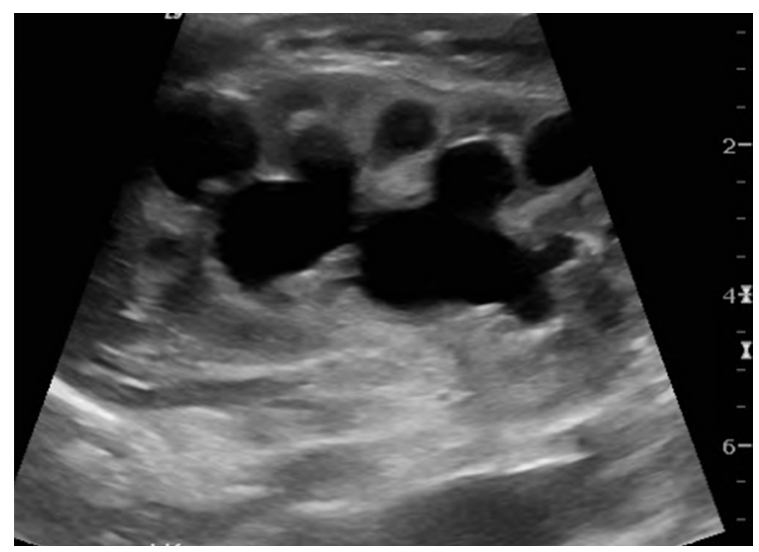

A

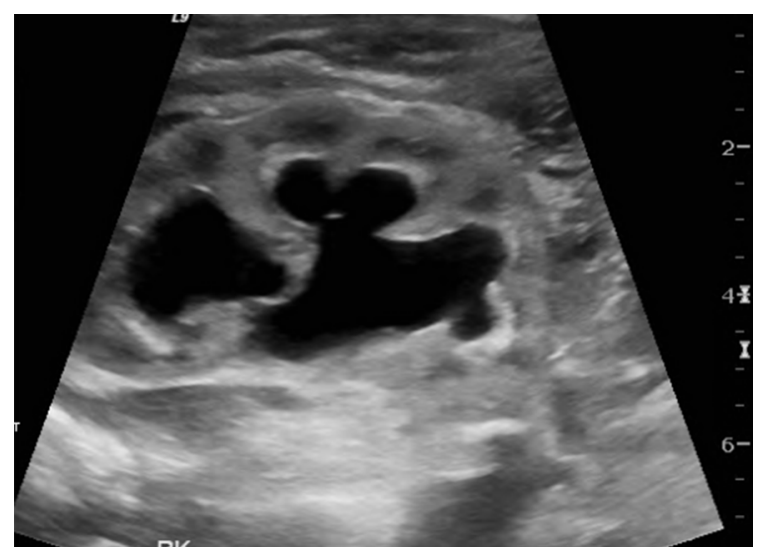

B

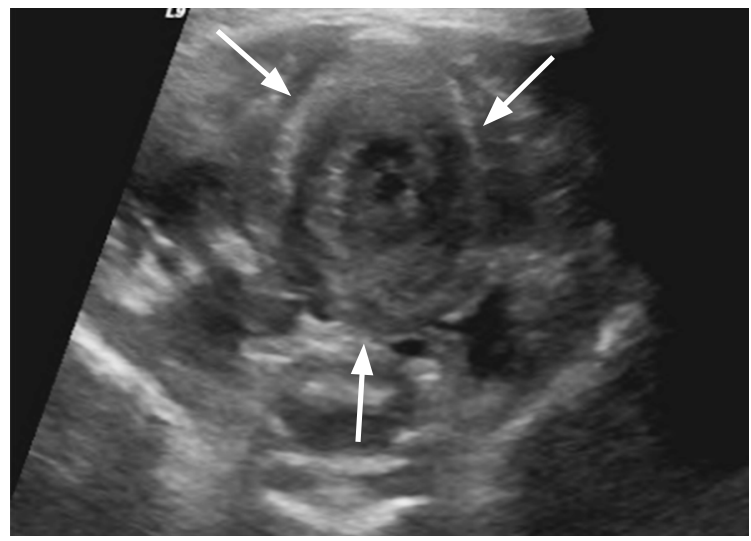

C
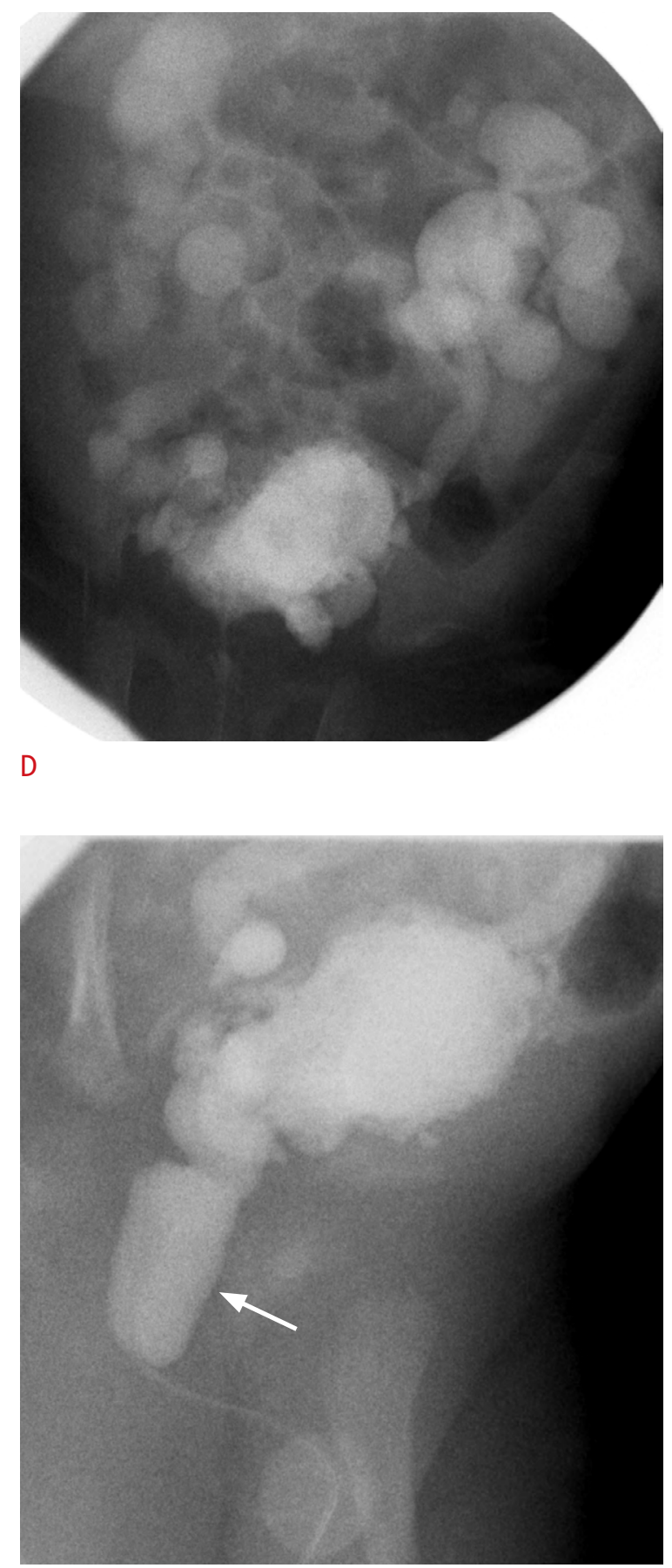

$\mathrm{E}$

Fig. 10. Posterior urethral valve.

A, B. Sonogram obtained immediately after birth in a male neonate shows significant hydronephrosis in the left (A) and right (B) kidneys. C. Transverse sonogram of the pelvis shows a collapsed bladder with thickened wall (arrows). D, E. Voiding cystourethrography shows severe reflux bilaterally, multiple bladder diverticula, and a distended posterior urethra (arrow), consistent with posterior urethral valve. 
and bladder neck, posterior urethra, or genital ducts such as the seminal vesicle, vas deferens, or ejaculatory duct in boys [40].

Uncomplicated cases of duplex kidney may be difficult to diagnose by US. The affected kidney is often longer and has a prominent parenchymal column that appears to separate the sinus fat, which provides indirect evidence of collecting system duplication [50]. High-resolution US may allow direct visualization of two renal pelvises with two separate proximal ureters [51]. More commonly, complete duplications will present with upper moiety hydronephrosis (Fig. 9). Dilation of the lower moiety may be seen due to reflux or less often, concomitant ureteropelvic junction obstruction [52]. In this situation, an important diagnostic clue for duplex kidney is the uneven pelvocalyceal dilation, which is unlike the pelvocalyceal dilation seen in other urinary abnormalities. US of the bladder may show a thin-walled intraluminal cystic structure indicative of ureterocele, and occasionally the parenchyma of the upper moiety appears hyperechoic with small cysts caused by accompanying dysplasia [3].

\section{Posterior Urethral Valve}

Posterior urethral valve is the most common cause of urethral obstruction in male patients [53]. Posterior urethral valve is presumed to be due to congenital membranous folds of Wolffian duct origin that cause variable degrees of obstruction at the junction of the penile and posterior urethra $[2,40]$. It is suggested when prenatal US shows bilateral hydroureteronephrosis associated with a thick-walled bladder and oligohydramnios [2], and the postnatal diagnosis is typically confirmed by voiding cystourethrography demonstrating a dilated posterior urethra with an abrupt transition to a small bulbous urethra at the level of the valve [53]. A coarse, trabeculated bladder and severe bilateral vesicoureteral reflux are also noted on voiding cystourethrography. Similarly, US findings include bilateral hydroureteronephrosis, an irregular thick-walled urinary bladder with or without associated bladder diverticula, and a dilated prostatic urethra (Fig. 10) [3]. In young infants, transperineal US can image posterior urethral dilation more clearly than conventional transabdominal scanning [54]. Posterior urethral valve should always be suspected when bilateral severe hydroureteronephrosis is noted while imaging male infants. The prognosis may be poor. Early renal failure can occur due to renal dysplasia, and progressive renal failure can follow even after treatment, possibly due to abnormal bladder function [55].

\section{Conclusion}

Here, we review causes of hydronephrosis in the newborn. Congenital hydronephrosis does not equate to obstruction; therefore, careful follow-up with US is warranted in almost all cases. Adherence to the SFU grading system is recommended for assessment of neonatal hydronephrosis. Postnatal causes of perinatal hydronephrosis should also be included in the differential diagnosis of hydronephrosis in the newborn.

ORCID: Young Hun Choi: http://orcid.org/0000-0002-1842-9062; Jung-Eun Cheon: http://orcid.org/0000-0003-1479-2064; Woo Sun Kim: http://orcid.org/0000-00032184-1311; In-One Kim: http://orcid.org/0000-0001-5800-3536

\section{Conflict of Interest}

No potential conflict of interest relevant to this article was reported.

\section{References}

1. Riccabona M. Assessment and management of newborn hydronephrosis. World J Urol 2004;22:73-78.

2. Epelman M, Victoria T, Meyers KE, Chauvin N, Servaes S, Darge K. Postnatal imaging of neonates with prenatally diagnosed genitourinary abnormalities: a practical approach. Pediatr Radiol 2012;42 Suppl 1:S124-S141.

3. Siegel MJ. Urinary tract. In: Siegel MJ, ed. Pediatric sonography. Philadelphia: Lippincott Williams \& Wilkins, 2011;384-460.

4. Nguyen HT, Herndon CD, Cooper C, Gatti J, Kirsch A, Kokorowski $P$, et al. The Society for Fetal Urology consensus statement on the evaluation and management of antenatal hydronephrosis. J Pediatr Urol 2010;6:212-231.

5. Ek S, Lidefeldt KJ, Varricio L. Fetal hydronephrosis; prevalence, natural history and postnatal consequences in an unselected population. Acta Obstet Gynecol Scand 2007;86:1463-1466.

6. Mallik M, Watson AR. Antenatally detected urinary tract abnormalities: more detection but less action. Pediatr Nephrol 2008;23:897-904

7. Kitchens DM, Herndon CD. Antenatal hydronephrosis. Curr Urol Rep 2009;10:126-133.

8. Ahmad G, Green P. Outcome of fetal pyelectasis diagnosed antenatally. J Obstet Gynaecol 2005;25:119-122.

9. Coelho GM, Bouzada MC, Pereira AK, Figueiredo BF, Leite MR, Oliveira DS, et al. Outcome of isolated antenatal hydronephrosis: a prospective cohort study. Pediatr Nephrol 2007;22:1727-1734.

10. Sinha A, Bagga A, Krishna A, Bajpai M, Srinivas M, Uppal R, et al. Revised guidelines on management of antenatal hydronephrosis. Indian J Nephrol 2013;23:83-97.

11. Wiener JS, O'Hara SM. Optimal timing of initial postnatal ultrasonography in newborns with prenatal hydronephrosis. J Urol 2002;168(4 Pt 2):1826-1829.

12. Laing FC, Burke VD, Wing VW, Jeffrey RB Jr, Hashimoto B. Postpartum evaluation of fetal hydronephrosis: optimal timing for follow-up sonography. Radiology 1984;152:423-424. 
13. Fernbach SK, Maizels M, Conway JJ. Ultrasound grading of hydronephrosis: introduction to the system used by the Society for Fetal Urology. Pediatr Radiol 1993;23:478-480.

14. Keays MA, Guerra LA, Mihill J, Raju G, Al-Asheeri N, Geier P, et al. Reliability assessment of Society for Fetal Urology ultrasound grading system for hydronephrosis. J Urol 2008;180:1680-1682.

15. Platt JF. Duplex Doppler evaluation of native kidney dysfunction: obstructive and nonobstructive disease. AJR Am J Roentgenol 1992;158:1035-1042.

16. Tublin ME, Bude RO, Platt JF. Review. The resistive index in renal Doppler sonography: where do we stand? AJR Am J Roentgenol 2003; 180:885-892.

17. Rawashdeh YF, Djurhuus JC, Mortensen J, Horlyck A, Frokiaer J. The intrarenal resistive index as a pathophysiological marker of obstructive uropathy. J Urol 2001;165:1397-1404.

18. de Bessa J Jr, Denes FT, Chammas MC, Cerri L, Monteiro ED, Buchpiguel CA, et al. Diagnostic accuracy of color Doppler sonographic study of the ureteric jets in evaluation of hydronephrosis. J Pediatr Urol 2008;4:113-117.

19. Cvitkovic Kuzmic A, Brkljacic B, Rados M, Galesic K. Doppler visualization of ureteric jets in unilateral hydronephrosis in children and adolescents. Eur J Radiol 2001;39:209-214.

20. Sohn B, Kim MJ, Han SW, Im YJ, Lee MJ. Shear wave velocity measurements using acoustic radiation force impulse in young children with normal kidneys versus hydronephrotic kidneys. Ultrasonography 2014;33:116-121.

21. Riccabona M, Fritz GA, Schollnast $H$, Schwarz T, Deutschmann MJ, Mache CJ. Hydronephrotic kidney: pediatric three-dimensional US for relative renal size assessment: initial experience. Radiology 2005;236:276-283.

22. Lidefelt KJ, Herthelius M. Antenatal hydronephrosis: infants with minor postnatal dilatation do not need prophylaxis. Pediatr Nephrol 2008;23:2021-2024.

23. Sidhu G, Beyene J, Rosenblum ND. Outcome of isolated antenatal hydronephrosis: a systematic review and meta-analysis. Pediatr Nephrol 2006;21:218-224.

24. Mami C, Paolata A, Palmara A, Marrone T, Berte LF, Marseglia $L$, et al. Outcome and management of isolated moderate renal pelvis dilatation detected at postnatal screening. Pediatr Nephrol 2009:24:2005-2008.

25. Khrichenko D, Darge K. Functional analysis in MR urography: made simple. Pediatr Radiol 2010;40:182-199.

26. Vivier PH, Dolores M, Taylor M, Elbaz F, Liard A, Dacher JN. MR urography in children. Part 1: how we do the F0 technique. Pediatr Radiol 2010;40:732-738.

27. Renjen P, Bellah R, Hellinger JC, Darge K. Pediatric urologic advanced imaging: techniques and applications. Urol Clin North Am 2010;37:307-318.

28. Sharman G, Sharma A. Postnatal management of antenatally detected hydronephrosis. World J Clin Urol 2014;3:283-294.

29. Gatti JM, Broecker BH, Scherz HC, Perez-Brayfield MR, Kirsch AJ. Antenatal hydronephrosis with postnatal resolution: how long are postnatal studies warranted? Urology 2001;57:1178.

30. Matsui F, Shimada K, Matsumoto F, Takano S. Late recurrence of symptomatic hydronephrosis in patients with prenatally detected hydronephrosis and spontaneous improvement. J Urol 2008; 180:322-325.

31. Koff SA, Campbell K. Nonoperative management of unilateral neonatal hydronephrosis. J Urol 1992;148(2 Pt 2):525-531.

32. Anderson NG, Fischer J, Leighton D, Hector-Taylor J, McEwing RL. Management in children of mild postnatal renal dilatation but without vesicoureteral reflux. Pediatr Nephrol 2010;25:477-483.

33. Lee RS, Cendron M, Kinnamon DD, Nguyen HT. Antenatal hydronephrosis as a predictor of postnatal outcome: a metaanalysis. Pediatrics 2006;118:586-593.

34. Sairam S, Al-Habib A, Sasson S, Thilaganathan B. Natural history of fetal hydronephrosis diagnosed on mid-trimester ultrasound. Ultrasound Obstet Gynecol 2001;17:191-196.

35. Harding LJ, Malone PS, Wellesley DG. Antenatal minimal hydronephrosis: is its follow-up an unnecessary cause of concern? Prenat Diagn 1999;19:701-705.

36. Becker AM. Postnatal evaluation of infants with an abnormal antenatal renal sonogram. Curr Opin Pediatr 2009;21:207-213.

37. Yiee JH, Johnson-Welch S, Baker LA, Wilcox DT. Histologic differences between extrinsic and intrinsic ureteropelvic junction obstruction. Urology 2010;76:181-184.

38. Mercado-Deane MG, Beeson JE, John SD. US of renal insufficiency in neonates. Radiographics 2002;22:1429-1438.

39. Hodges SJ, Werle D, McLorie G, Atala A. Megaureter. ScientificWorldJournal 2010;10:603-612.

40. Berrocal T, Lopez-Pereira P, Arjonilla A, Gutierrez J. Anomalies of the distal ureter, bladder, and urethra in children: embryologic, radiologic, and pathologic features. Radiographics 2002;22:11391164.

41. Lee MJ. Congenital anomalies of the upper urinary tract. In: Kim IO, ed. Radiology illustrated: pediatric radiology. Heidelberg: SpringerVerlag, 2014;723-757.

42. Shukla AR, Cooper J, Patel RP, Carr MC, Canning DA, Zderic SA, et al. Prenatally detected primary megaureter: a role for extended followup. J Urol 2005;173:1353-1356.

43. Bates DG, Riccabona M. Vesicoureteral reflux. In: Coley BD, ed. Caffey's pediatric diagnostic imaging. Philadelphia: Saunders, 2013;1253-1261.

44. Lebowitz RL, Olbing H, Parkkulainen KV, Smellie JM, TamminenMobius TE. International system of radiographic grading of vesicoureteric reflux. International Reflux Study in Children. Pediatr Radiol 1985;15:105-109.

45. Estrada CR Jr, Passerotti CC, Graham DA, Peters CA, Bauer SB, 
Diamond DA, et al. Nomograms for predicting annual resolution rate of primary vesicoureteral reflux: results from 2,462 children. J Urol 2009;182:1535-1541.

46. Robben SG, Boesten M, Linmans J, Lequin MH, Nijman RM. Significance of thickening of the wall of the renal collecting system in children: an ultrasound study. Pediatr Radiol 1999;29:736-740.

47. Berrocal T, Gaya F, Arjonilla A, Lonergan GJ. Vesicoureteral reflux: diagnosis and grading with echo-enhanced cystosonography versus voiding cystourethrography. Radiology 2001;221:359-365.

48. Darge K. Voiding urosonography with ultrasound contrast agents for the diagnosis of vesicoureteric reflux in children. I. Procedure. Pediatr Radiol 2008;38:40-53.

49. Han TI. Cystic renal disease and neoplasms. In: Kim IO, ed. Radiology illustrated: pediatric radiology. Heidelberg: SpringerVerlag, 2014;759-792.

50. Dillman JR, Bates DG. Congenital and neonatal abnormalities. In:
Coley BD, ed. Caffey's pediatric diagnostic imaging. Philadelphia: Saunders, 2013;1195-1208.

51. Riccabona M. The ureter and vesicoureteral reflux. In: Slovis TL, ed. Caffey's pediatric diagnostic imaging. Philadelphia: Mosby, 2008;2315-2355.

52. Fernbach SK, Feinstein KA, Spencer K, Lindstrom CA. Ureteral duplication and its complications. Radiographics 1997;17:109-127.

53. Shin SM. Bladder and urethra disease. In: Kim IO, ed. Radiology illustrated: pediatric radiology. Heidelberg: Springer-Verlag, 2014;803-834.

54. Cohen HL, Susman M, Haller JO, Glassberg KI, Shapiro MA, Zinn DL. Posterior urethral valve: transperineal US for imaging and diagnosis in male infants. Radiology 1994;192:261-264.

55. Nasir AA, Ameh EA, Abdur-Rahman LO, Adeniran JO, Abraham MK. Posterior urethral valve. World J Pediatr 2011;7:205-216. 